\title{
Primary Care Attributes and Mortality: A National Person-Level Study
}

\author{
Anthony Jerant, MD \\ Josbua J. Fenton, MD, MPH \\ Peter Franks, MD
}

Department of Family and Community Medicine, Center for Healthcare Policy and Research, University of California Davis School of Medicine, Sacramento, California

\begin{abstract}
PURPOSE Research demonstrates an association between the geographic concentration of primary care clinicians and mortality in the area, but there is limited evidence of a mortality benefit of primary care at the individual patient level. We examined whether patient-reported access to selected primary care attributes, including some emphasized in the medical home literature, is associated with lower individual mortality risk.
\end{abstract}

METHODS We analyzed data from 2000-2005 Medical Expenditure Panel Survey respondents aged 18 to 90 years $(N=52,241)$, linked to the National Death Index through 2006. A score was constructed from 5 yes/no items assessing whether the respondent's usual source of care had 3 attributes: comprehensiveness, patient-centeredness, and enhanced access. Scores ranged from 0 to 1 (higher scores $=$ more attributes). We examined the association between the primary care attributes score and mortality during up to 6 years of follow-up using Cox survival analysis, adjusted for social, demographic, and health-related characteristics.

RESULTS Racial/ethnic minorities, poorer and less educated persons, individuals without private insurance, healthier persons, and residents of regions other than the Northeast reported less access to primary care attributes than others. The primary care attributes score was inversely associated with mortality (adjusted hazard ratio $=0.79 ; 95 \%$ confidence interval, 0.64-0.98; $P=.03$ ); supplementary analyses showed mortality decreased linearly with increasing score.

CONCLUSIONS Greater reported patient access to selected primary care attributes was associated with lower mortality. The findings support the current interest in ensuring that patients have access to a medical home encompassing these attributes.

Ann Fam Med 2012;10:34-41. doi:10.1370/afm.1314

\section{INTRODUCTION}

$\mathrm{P}$ rior studies, particularly those conducted by Starfield et al, ${ }_{1}$ indicate that geographic areas with higher concentrations of primary care clinicians tend to have lower mortality. In these ecologic studies, with populations rather than individual patients as the unit of analysis, primary care clinicians were identified based on specialty. Starfield and colleagues also developed a definition of primary care based on several core attributes, largely consistent with an earlier Institute of Medicine report: provision of first contact care, and longitudinal delivery of comprehensive, coordinated, and patient-centered care. ${ }^{2,3}$ Historically, practices delivering care possessing such attributes have been referred to informally as medical homes. ${ }^{4}$ More recently, the core primary care attributes were encompassed formally within the more expansive Joint Principles of the Patient-Centered Medical Home, which specifies further attributes, including enhanced access to care via expanded (eg, evening or weekend) hours and other methods. ${ }^{5}$

Whether access to specific primary care attributes is associated with lower mortality at the individual patient level is uncertain, however, given 
the ecologic designs of the aforementioned studies. ${ }^{6}$ A potential pitfall in interpreting the findings of such studies is the ecologic fallacy: falsely concluding that aggregate statistics collected for a group are applicable to individuals within the group. ${ }^{7}$ Studies with individuals as the unit of analysis are needed to examine the association of specific primary care attributes with mortality at the patient level.

To address these issues, we analyzed longitudinal patient-level data from the 2000-2005 Medical Expenditure Panel Surveys (MEPS) ${ }_{1}^{8}$ linked to the National Death Index (NDI). ${ }^{9}$ The MEPS includes measures tapping aspects of 3 specific primary care attributes with plausible influence on individual mortality risk: comprehensiveness, patient-centeredness, and enhanced access. To the extent that primary care is comprehensive, patient-centered care, and available to patients when needed, patients may be more likely to receive the timely preventive, acute, and chronic care that have been shown to reduce mortality. ${ }^{10}$ Increased access to these attributes might also minimize unnecessary and potentially harmful care, ${ }^{1,11-14}$ thereby mitigating iatrogenic mortality. ${ }^{15-19}$ We therefore hypothesized greater patient-reported access to these primary care attributes would be associated with decreased subsequent mortality risk

\section{METHODS}

\section{Data Sources}

The MEPS is an annual national survey of health care use and costs in the US civilian, noninstitutionalized population, using an overlapping panel design. ${ }^{8}$ Individual data are collected over a 2 -year period through 6 interviews. The MEPS Household Component includes information on health care features, social and demographic characteristics, health insurance, and health care expenditures. A self-administered questionnaire in both years includes items on chronic health conditions and health status. Details regarding items on the questionnaire are available online (http://www .meps.ahrq.gov/mepsweb/survey_comp/survey.jsp). In the current study, we used first-year responses. The full-year response rate varied from $70.5 \%$ to $66.5 \%$ for the 6 panels of data (2000-2005) we used. ${ }^{8}$

The MEPS Household Component sample is a subsample of households included in the previous year's National Health Interview Survey (NHIS), conducted annually by the National Center for Health Statistics. The NHIS is linked to death certificate data in the NDI, a central computerized index of US death record information on file in state vital statistics offices, in turn permitting linkage to the MEPS. ${ }^{9}$ The analytic sample for this study included all persons aged 18 to
90 years in their first year of participation in the MEPS who provided baseline data and for whom mortality information was available.

\section{Measures}

\section{Primary Care Attributes}

Respondents reported whether they had a particular doctor's office, clinic, health center, or other place they visited when sick or needing advice about health, that is, a usual source of health care (USOC). For those reporting a USOC, we constructed a summary primary care attributes measure from 5 additional yes/no items assessing respondent perceptions of their USOC during the preceding 12 months. Three items related to comprehensiveness, asking whether the USOC provided (1) care for new health problems, (2) preventive care, and (3) referrals to other health care professionals. A fourth item concerned enhanced access, asking whether the USOC offered night and weekend hours. The fifth item concerned patient-centeredness, asking whether the USOC generally listened to and sought the respondent's advice when choosing between treatments. For each of the 5 attributes items, possible responses were yes ( 1 point) and no ( 0 points). Respondents indicating no USOC had 0 points assigned for all 5 items. We used the mean of all affirmative responses to the attributes questions (total yes responses divided by total items not missing a response). Possible scores ranged from 0 to 1 , with higher scores indicating more primary care attributes (Cronbach $\alpha$ in this sample $=.53$ ).

\section{Social and Demographic Characteristics}

The social and demographic characteristics examined were age in years; sex; race/ethnicity (Hispanic, white, black, or other), US Census region (West, Midwest, Northeast, South); residence (living in a Metropolitan Statistical Area or not); education level (0-8 years formal schooling [less than high school], 9-11 years [some high school], 12 years [high school graduate], 13-15 years [some college], $\geq 16$ years [college graduate]); household income level (<100\%, 100\%-124\%, 125\%$199 \%, 200 \%-399 \%$, or $\geq 400 \%$ of the federal poverty level); and health insurance status (uninsured, privately insured, or publicly insured).

\section{Health-Related Characteristics}

Mental and physical health status were measured with the 12-Item Short Form Health Survey Mental Component Summary (MCS-12) and Physical Component Summary (PCS-12) scores. ${ }^{20}$ Scores range from 0 to 100, with higher scores indicating better health. We also included a single-item that measures global selfrated health, given its association with mortality independent of mental and physical health status. ${ }^{21}$ The 
item asks, "In general, would you say your health is: excellent, very good, good, fair, or poor?"

Respondents reported 8 chronic conditions: diabetes, hypertension, coronary heart disease, myocardial infarction, cerebrovascular disease, asthma, emphysema, and arthritis. Self-reported height and weight data were used to construct body mass index (BMI). Self-reported smoking status was dichotomized as current smoker or not. Detailed information about health care use (hospitalizations, emergency department visits, outpatient hospital visits, office-based visits, dental visits, home health care, prescription medications, and ancillary care) was used to generate standardized expenditures for each item of use, summed to yield total expenditures for each year. This measure was included to capture otherwise unmeasured morbidity.

\section{Mortality}

We assessed mortality via the NDI through the end of December 2006 with the public-use version of the NHIS-linked mortality files. ${ }^{9}$ A calibration study reported that, overall, $98.5 \%$ of respondents are correctly classified by their death date or as alive. ${ }^{22}$ Survival was measured in quarters from the time of the health measure self-assessment until time of death, or the respondent was considered censored if alive on December 31, 2006. ${ }^{9}$

\section{Data Analysis}

We analyzed data using Stata version 11.2 (Stata Corporation, College Station, Texas), adjusting for the complex survey design of MEPS. Data were analyzed using longitudinal strata and primary sampling unit identifiers and survey weights, to account for the nonrandom sampling technique of the survey.

Analyses examining associations between the primary care attributes score (as a continuous variable) and mortality used Cox proportional hazards survival models. The proportional hazards assumption was examined in each analysis both graphically and statistically, and no statistically significant evidence of violation was found. Analyses adjusted for social and demographic characteristics (age, sex, race/ethnicity, residence, Census region, education level, household income level, and health insurance status) and healthrelated characteristics (mental health status [MCS-12], physical health status [PCS-12], self-rated health, health conditions [count of 8 chronic conditions], and health expenditures). Analyses also adjusted for MEPS panel year, included as a categorical variable, to account for potential secular temporal trends.

In supplementary analyses, we repeated regression models excluding persons without a USOC. We also modeled mortality in the entire sample with the primary care attributes score as a grouped ordinal variable, using cut points based on both sample size considerations and numbers of primary care attributes: 0 to 0.5 (corresponding to either no USOC or affirmative responses to $\leq 2$ of the 5 attributes yes/no questions), 0.6 to 0.75 (yes answers to 3 of 5 questions), 0.8 (yes answers to 4 of 5 questions), and 1 (yes answers to all 5 questions). We also modeled mortality in the entire sample with the primary care attributes score and a squared attributes term (to explore potential nonlinearity). A final analysis also included smoking status (smoker or not) and BMI category $(<20,20$ to $<25,25$ to $<30$, and $\geq 30 \mathrm{~kg} / \mathrm{m}^{2}$ ) to adjust for health risk behaviors. These health risks were not included in the primary analyses because of concerns they might be affected by primary care attributes, and because $4 \%$ of the analytic sample had missing data for these variables.

\section{RESULTS}

In all, 66,952 eligible adults aged 18 to 90 years entered the MEPS cohorts between 2000 and 2005; 60,199 (90.2\%, population weighted) had complete baseline data. Mortality ascertainment was available for 52,241 persons $(91.8 \%$, population weighted, of those with complete baseline data), of whom 1,717 died $(3.1 \%$, population weighted), accounting for a total of 816,033 person-quarters. Numbers of respondents with missing primary care attribute items were as follows: new problems, $57(0.11 \%)_{i}$ preventive care, $39(0.07 \%)_{i}$ referrals, $88(0.17 \%)$; patient-centeredness 1,491 $(2.85 \%)$; and enhanced access 3,486 (6.67\%).

Table 1 summarizes the characteristics of the analytic sample by primary care attributes score category. Slightly more than one-quarter of respondents (26.8\%) had yes responses to all 5 primary care attributes items (ie, attributes score $=1.0$ ). Respondents with more affirmative attribute item responses were more likely to be female and white; have higher income and more education, live in the Northeast; have private insurance; report more chronic medical problems; be older; have lower PCS-12 scores and less than excellent self-rated health; and have higher health expenditures.

Table 2 shows the adjusted associations between respondent characteristics and mortality. The primary care attributes score was inversely associated with mortality. Supplementary analyses excluding the $21 \%$ of individuals lacking a USOC (leaving a sample of $40,157)$ yielded a similar hazard ratio for the primary care attributes score, although it was not statistically significant (adjusted hazard ratio $=0.81 ; 95 \%$ confidence interval, $0.55-1.18 ; P=.27$ ).

Table 3 shows that the adjusted mortality hazard by primary care attributes score category (refer- 


\begin{tabular}{|c|c|c|c|c|c|}
\hline \multirow[b]{2}{*}{ Characteristic } & \multicolumn{5}{|c|}{ Primary Care Attributes Score } \\
\hline & $\begin{array}{c}0-0.5 \\
(n=13,071)\end{array}$ & $\begin{array}{c}0.6-0.75 \\
(n=6,431)\end{array}$ & $\begin{aligned} & 0.8 \\
&(n=19,527)\end{aligned}$ & $\begin{aligned} & 1.0 \\
(n= & 13,212)\end{aligned}$ & $\begin{array}{c}\text { Total } \\
(\mathrm{N}=52,241)\end{array}$ \\
\hline Sample distribution ${ }^{\mathrm{a}}$ & $22.9(0.4)$ & $12.8(0.3)$ & $37.5(0.4)$ & $26.8(0.5)$ & - \\
\hline \multicolumn{6}{|c|}{ Categorical characteristics $^{a}$} \\
\hline Female & $42.2(0.4)$ & $55.5(0.5)$ & $56.8(0.2)$ & $54.4(0.3)$ & $52.4(0.1)$ \\
\hline \multicolumn{6}{|l|}{ Race/ethnicity } \\
\hline White & $58.5(0.8)$ & $74.9(0.7)$ & $74.6(0.6)$ & $73.6(0.7)$ & $70.4(0.6)$ \\
\hline Hispanic & $21.2(0.8)$ & $8.7(0.5)$ & $9.5(0.4)$ & $9.6(0.4)$ & $12.3(0.5)$ \\
\hline Black & $12.7(0.5)$ & $9.7(0.5)$ & $10.2(0.4)$ & $10.5(0.4)$ & $10.8(0.4)$ \\
\hline Other & $7.6(0.3)$ & $6.8(0.4)$ & $5.7(0.3)$ & $6.2(0.3)$ & $6.4(0.2)$ \\
\hline \multicolumn{6}{|l|}{ Income, \% of FPL } \\
\hline$<100 \%$ & $14.9(0.4)$ & $10.4(0.4)$ & $9.8(0.3)$ & $8.6(0.3)$ & $10.8(0.2)$ \\
\hline $100 \%$ to $<125 \%$ & $5.5(0.2)$ & $4.1(0.3)$ & $3.8(0.1)$ & $3.6(0.2)$ & $4.2(0.1)$ \\
\hline $125 \%$ to $<200 \%$ & $16.8(0.4)$ & $13.0(0.5)$ & $12.8(0.3)$ & $11.3(0.3)$ & $13.4(0.2)$ \\
\hline $200 \%$ to $<400 \%$ & $31.9(0.4)$ & $30.8(0.6)$ & $30.9(0.4)$ & $30.9(0.5)$ & $31.1(0.3)$ \\
\hline$\geq 400 \%$ & $30.9(0.6)$ & $41.7(0.7)$ & $42.7(0.5)$ & $45.6(0.7)$ & $40.4(0.4)$ \\
\hline \multicolumn{6}{|l|}{ Education } \\
\hline No high school & $7.8(0.3)$ & $6.3(0.3)$ & $6.3(0.2)$ & $4.9(0.2)$ & $6.3(0.2)$ \\
\hline Some high school & $14.6(0.3)$ & $11.7(0.4)$ & $10.9(0.2)$ & $10.4(0.3)$ & $11.8(0.2)$ \\
\hline High school graduate & $32.8(0.5)$ & $33.6(0.6)$ & $32.2(0.4)$ & $32.1(0.5)$ & $32.5(0.3)$ \\
\hline Some college & $22.0(0.4)$ & $22.8(0.5)$ & $23.9(0.3)$ & $23.7(0.3)$ & $23.2(0.2)$ \\
\hline College graduate & $22.8(0.6)$ & $25.7(0.7)$ & $26.7(0.5)$ & $28.9(0.6)$ & $26.2(0.4)$ \\
\hline Urban residence & $84.5(0.8)$ & $80.0(1.1)$ & $79.0(1.0)$ & $85.9(0.7)$ & $82.3(0.7)$ \\
\hline \multicolumn{6}{|l|}{ US Census region } \\
\hline Northeast & $12.2(0.6)$ & $18.3(1.1)$ & $17.5(0.7)$ & $26.1(1.1)$ & $18.6(0.7)$ \\
\hline Midwest & $19.8(0.9)$ & $23.2(1.1)$ & $22.1(0.8)$ & $25.7(1.0)$ & $22.7(0.7)$ \\
\hline South & $41.6(1.4)$ & $36.4(1.3)$ & $39.5(1.1)$ & $27.2(1.0)$ & $36.3(1.0)$ \\
\hline West & $26.4(1.3)$ & $22.1(1.3)$ & $20.9(1.0)$ & $21.0(1.0)$ & $22.4(1.0)$ \\
\hline \multicolumn{6}{|l|}{ Health insurance } \\
\hline Private & $58.1(0.6)$ & $73.6(0.6)$ & $75.3(0.5)$ & $79.0(0.4)$ & $71.9(0.4)$ \\
\hline Public & $9.7(0.3)$ & $18.4(0.6)$ & $16.6(0.4)$ & $13.3(0.4)$ & $14.2(0.3)$ \\
\hline None & $32.3(0.6)$ & $8.0(0.4)$ & $8.1(0.2)$ & $7.6(0.2)$ & $13.9(0.2)$ \\
\hline
\end{tabular}

ence category $=0-0.5)$ decreased monotonically with increasing attributes. In the analytic model including both primary care attributes score and (primary care attributes score - mean primary care attributes score $)^{2}$, the squared term was not significantly associated with mortality (adjusted hazard ratio $=0.99 ; 95 \%$ confidence interval, $0.50-1.97 ; P=.98)$, suggesting a linear relationship between the attributes score and mortality. Finally, in the analysis including smoking status and BMI $(\mathrm{N}=50,260)$, the association between the attributes score and mortality remained significant (adjusted hazard ratio $=0.81,95 \%$ confidence interval, 0.66-0.99; $P=.04)$.

\section{DISCUSSION}

In a national study, we found that higher patientreported access to selected, specific primary care attri- butes was associated with a lower individual mortality risk during a follow-up of up to 6 years. Our findings complement and expand on those of prior ecologic studies that demonstrated lower mortality rates within geographic areas with relatively higher concentrations of primary care clinicians, defined based on specialty. By comparison, our findings suggest an individual patient-level mortality benefit resulting from greater access to particular primary care attributes.

Of the 3 clinician attributes we studied, comprehensiveness and patient-centeredness are established core elements of primary care. ${ }^{2,3}$ They also feature prominently, however, in contemporary medical home definitions proposed by various stakeholders, ${ }^{4,5}$ including the Joint Principles of the Patient-Centered Medical Home, ${ }^{5}$ a blueprint for primary care practice redesign. ${ }^{23,24}$ The third attribute, evening or weekend access to a USOC, relates to the imperative for 


\begin{tabular}{|c|c|c|c|c|c|}
\hline \multirow[b]{2}{*}{ Characteristic } & \multicolumn{5}{|c|}{ Primary Care Attributes Score } \\
\hline & $\begin{array}{c}0-0.5 \\
(n=13,071)\end{array}$ & $\begin{array}{l}0.6-0.75 \\
(n=6,431)\end{array}$ & $\begin{aligned} & 0.8 \\
&(n=19,527)\end{aligned}$ & $\begin{aligned} & 1.0 \\
(n= & 13,212)\end{aligned}$ & $\begin{array}{c}\text { Total } \\
(\mathrm{N}=52,241)\end{array}$ \\
\hline \multicolumn{6}{|l|}{ Categorical characteristicsa (continued) } \\
\hline \multicolumn{6}{|l|}{ No. of chronic health conditions } \\
\hline 0 & $72.9(0.4)$ & $43.8(0.7)$ & $43.3(0.5)$ & $51.1(0.5)$ & $52.7(0.3)$ \\
\hline 1 & $17.8(0.3)$ & $28.3(0.5)$ & $27.0(0.3)$ & $26.2(0.3)$ & $24.7(0.2)$ \\
\hline 2 & $6.4(0.2)$ & $17.0(0.4)$ & $16.9(0.3)$ & $13.6(0.3)$ & $13.4(0.2)$ \\
\hline 3 & $1.9(0.1)$ & $6.8(0.3)$ & $7.6(0.2)$ & $5.6(0.2)$ & $5.6(0.1)$ \\
\hline$\geq 4$ & $1.0(0.1)$ & $4.1(0.2)$ & $5.1(0.1)$ & $3.5(0.2)$ & $3.6(0.1)$ \\
\hline \multicolumn{6}{|l|}{ Self-rated health } \\
\hline Excellent & $30.5(0.5)$ & $23.5(0.6)$ & $21.5(0.4)$ & $24.8(0.4)$ & $24.8(0.3)$ \\
\hline Very good & $34.1(0.4)$ & $33.9(0.6)$ & $33.6(0.4)$ & $35.9(0.5)$ & $34.4(0.3)$ \\
\hline Good & $26.4(0.4)$ & $27.8(0.5)$ & $28.7(0.3)$ & $26.7(0.4)$ & $27.5(0.2)$ \\
\hline Fair & $7.3(0.2)$ & $11.4(0.4)$ & $11.9(0.2)$ & $9.5(0.3)$ & $10.1(0.2)$ \\
\hline Poor & $1.7(0.1)$ & $3.4(0.2)$ & $4.3(0.1)$ & $3.0(0.1)$ & $3.2(0.1)$ \\
\hline Smoker & $27.6(0.5)$ & $20.0(0.5)$ & $19.3(0.3)$ & $19.7(0.4)$ & $21.5(0.2)$ \\
\hline \multicolumn{6}{|l|}{$\mathrm{BMI}, \mathrm{kg} / \mathrm{m}^{2}$} \\
\hline$<20$ & $6.5(0.2)$ & $5.6(0.3)$ & $5.3(0.1)$ & $5.6(0.2)$ & $5.7(0.1)$ \\
\hline 20 to $<25$ & $35.4(0.4)$ & $32.3(0.6)$ & $30.7(0.4)$ & $32.1(0.4)$ & $32.4(0.3)$ \\
\hline 25 to $<30$ & $35.5(0.4)$ & $35.5(0.5)$ & $35.3(0.3)$ & $35.2(0.4)$ & $35.4(0.2)$ \\
\hline$\geq 30$ & $22.6(0.4)$ & $26.6(0.5)$ & $28.6(0.3)$ & $27.0(0.4)$ & $26.5(0.2)$ \\
\hline \multicolumn{6}{|l|}{ Continuous characteristics } \\
\hline Age, mean (SD), y & $38.8(0.2)$ & $50.6(0.3)$ & $50.3(0.2)$ & $46.7(0.2)$ & $46.7(0.2)$ \\
\hline \multicolumn{6}{|l|}{ Health status, mean (SD), score } \\
\hline PCS-12 & $52.0(0.2)$ & $48.6(0.2)$ & $47.6(0.1)$ & $49.3(0.1)$ & $49.2(0.1)$ \\
\hline MCS-12 & $50.9(0.1)$ & $50.7(0.2)$ & $50.5(0.1)$ & $51.0(0.1)$ & $50.8(0.1)$ \\
\hline $\begin{array}{l}\text { Total annual health care expenditures, } \\
\text { mean (SD), \$ }\end{array}$ & $1,625(56)$ & $3,935(130)$ & $4,624(88)$ & $3,777(98)$ & $3,621(53)$ \\
\hline
\end{tabular}

enhanced access to primary care articulated in the Joint Principles blueprint. ${ }^{5}$

Given work suggesting the high importance of the 3 studied primary care attributes to the patient-centered medical home movement, ${ }^{25}$ we believe our findings have implications for the movement. Specifically, they suggest that adopting these elements of the medical home has the potential to reduce mortality, complementing evidence suggesting benefits of selected medical home elements on other important outcomes (eg, preventive services delivery rates, diabetic control, patient satisfaction), potentially at reduced cost. ${ }^{23,26,27}$ Multicenter randomized controlled trials of interventions will be necessary to definitively address the question of which medical home attributes contribute to reduced mortality risk.

The design of our study did not permit examination of the potential mechanisms by which greater access to these primary care attributes might reduce mortality; however, we speculate that enhanced access to comprehensive, patient-centered care facilitates timely delivery of evidence-based preventive, acute, and chronic care measures throughout the life cycle and across health conditions. Such care measures have been associated with lower mortality during periods comparable to the follow-up period in our study. ${ }^{10}$

Greater access to the studied primary care attributes might also mitigate iatrogenic mortality. ${ }^{15,17-19}$ Lack of extended primary care office hours is associated with increased emergency department use, ${ }^{13,14}$ increasing the risk of overly aggressive testing and treatment. ${ }^{16,17}$ Failure to offer comprehensive health care is associated with more hospitalizations and specialty referrals, ${ }_{1}$ again increasing the likelihood of overly aggressive care. Finally, a patient-centered clinician communication style is associated with less diagnostic testing and fewer specialty referrals, probably by more effectively addressing patient health concerns. ${ }^{11,12}$

Because respondents reporting more primary care attributes were also more likely to identify a USOC, 
Table 2. Adjusted Mortality Hazard by Primary Care Attributes Score and Other Respondent Characteristics $(\mathrm{N}=52,241)$

\begin{tabular}{|c|c|c|}
\hline Characteristic & $\begin{array}{l}\text { Adjusted Hazard } \\
\text { Ratio }(95 \% \mathrm{Cl})\end{array}$ & $P$ Value \\
\hline Primary care attributes score (range, 0-1.0) & $0.79(0.64-0.98)$ & .03 \\
\hline Age, per 10-year increment & $1.08(1.07-1.08)$ & $<.001$ \\
\hline Female & $0.54(0.47-0.62)$ & $<.001$ \\
\hline \multicolumn{3}{|c|}{ Income level (reference $<100 \%$ of federal poverty level) } \\
\hline $100 \%-124 \%$ & $1.07(0.80-1.43)$ & .63 \\
\hline $125 \%-199 \%$ & $1.05(0.86-1.29)$ & .63 \\
\hline $200 \%-399 \%$ & $1.01(0.84-1.21)$ & .92 \\
\hline$\geq 400 \%$ & $0.90(0.73-1.11)$ & .32 \\
\hline \multicolumn{3}{|l|}{ Education level (reference $=$ no high school) } \\
\hline Some high school & $1.06(0.88-1.27)$ & .55 \\
\hline High school graduate & $0.95(0.81-1.11)$ & .50 \\
\hline Some college & $0.94(0.75-1.17)$ & .56 \\
\hline College graduate & $0.85(0.68-1.06)$ & .14 \\
\hline \multicolumn{3}{|l|}{ Race/ethnicity (reference $=$ white) } \\
\hline Hispanic & $0.64(0.52-0.79)$ & $<.001$ \\
\hline Black & $1.23(1.02-1.47)$ & .03 \\
\hline Other & $0.94(0.67-1.32)$ & .73 \\
\hline Urban residence & $0.92(0.80-1.06)$ & .24 \\
\hline \multicolumn{3}{|l|}{ US Census geographic region (reference $=$ Northeast) } \\
\hline Midwest & $0.94(0.78-1.14)$ & .53 \\
\hline South & $1.06(0.89-1.25)$ & .53 \\
\hline West & $1.01(0.84-1.22)$ & .88 \\
\hline \multicolumn{3}{|l|}{ Health status } \\
\hline PCS-12 & $0.99(0.98-0.99)$ & .001 \\
\hline MCS-12 & $0.97(0.97-0.98)$ & $<.001$ \\
\hline No. of chronic health conditions & $1.05(1.01-1.10)$ & .02 \\
\hline \multicolumn{3}{|l|}{ Self-rated health (reference $=$ excellent) } \\
\hline Very good & $0.95(0.74-1.23)$ & .69 \\
\hline Good & $1.01(0.79-1.30)$ & .92 \\
\hline Fair & $1.31(0.99-1.74)$ & .06 \\
\hline Poor & $1.79(1.29-2.49)$ & .001 \\
\hline Total annual health care expenditures, per $\$ 1,000$ & $1.01(1.01-1.02)$ & $<.001$ \\
\hline \multicolumn{3}{|l|}{ Health insurance (reference = private) } \\
\hline Public & $1.11(0.96-1.28)$ & .16 \\
\hline None & $1.22(0.87-1.70)$ & .25 \\
\hline \multicolumn{3}{|c|}{$\begin{array}{l}\text { MCS-12 = Mental Component Summary score of the } 12 \text {-Item Short Form Health Survey; PCS-12 = Physical Com- } \\
\text { ponent Summary score of the } 12 \text {-Item Short Form Health Survey. }\end{array}$} \\
\hline \multicolumn{3}{|c|}{ Note: analyses also adjusted for Medical Expenditure Panel Survey panel year. } \\
\hline
\end{tabular}

Finally, we found evidence of potential socially and demographically based disparities in access to primary care attributes. Racial/ethnic minorities, poorer and less educated individuals, and persons lacking health insurance reported notably lower access to the attributes than others, a concerning finding in light of health disparities disfavoring these groups. ${ }^{28}$ Although the wider adoption of primary care attributes may have promise for mitigating health disparities, ${ }^{29}$ interventions to promote equitable access to such attributes may be required to fulfill this promise. We also found evidence of geographic variation in access to the attributes, suggesting the need for efforts to ensure uniform dissemination across regions.

Our study had some limitations. The analyses were observational, so a causal association between the primary care attributes we examined and mortality cannot be inferred. Missing covariates could explain the association between the attributes score and mortality. Healthconscious individuals, who have a relatively low mortality risk, may be more likely to report and capitalize on positive attributes of their USOC. On the other hand, the inverse relationship between the primary care attributes score and mortality is unlikely to be confounded by unmeasured morbidity, given that higher attri-

potentially confounding the relationship between primary care attributes and mortality, we conducted a sensitivity analysis excluding individuals lacking a USOC. In that analysis, the mortality hazard ratio for primary care score was similar to the hazard ratio derived in the main analysis (although, with the smaller sample size, no longer statistically significant). We also found mortality risk decreased linearly with increasing primary care attributes score. The observed association between primary care attributes and mortality therefore is not attributable to the availability of a USOC. butes scores were associated with lower health status, poorer self-rated health, more chronic conditions, and higher health care expenditures. The latter associations may appear paradoxic given that we hypothesize that the studied attributes may protect against mortality through improved health and reduced unnecessary

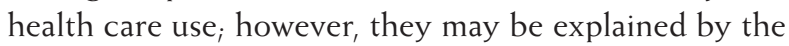
greater tendency of persons in worse health to seek out a USOC. We adjusted for health status, self-rated health, chronic conditions, and health care use and expenditures in our models to capture the complex, competing effects between these variables, primary 


\begin{tabular}{|c|c|c|}
\hline $\begin{array}{l}\text { Primary Care } \\
\text { Attributes Score }\end{array}$ & $\begin{array}{l}\text { Adjusted Hazard } \\
\text { Ratio }(95 \% \mathrm{Cl})\end{array}$ & $P$ Value \\
\hline 0-0.5 (reference) & 1.00 & - \\
\hline $0.6-0.75$ & $0.90(0.72-1.13)$ & .36 \\
\hline 0.8 & $0.83(0.68-1.02)$ & .07 \\
\hline 1.0 & $0.81(0.67-0.99)$ & .04 \\
\hline
\end{tabular}

Note: Analyses adjusted for age, sex, race/ethnicity, Census region, education level, household income level, health insurance status, mental and physical health status, global self-rated health, health conditions, health expenditures, and Medical Expenditure Panel Survey panel year.

care attributes, and mortality. Nonresponse to the MEPS may have also produced some bias, so that generalizability to nonresponders is uncertain. Still, MEPS data are likely the most representative data available to examine our research question.

Another limitation was that there were only 5 items in the MEPS indicating the presence or absence of a primary care attribute and using a common yes/no response option. Other primary care items in the MEPS focused on ratings of perceived quality of care with Likert-type response options. The 5 items used in our attributes scale were not designed to tap a unified construct, contributing to modest internal consistency and imposing a limit on predictive ability. Two of the study primary care attributes were assessed with only single items. We did not weight items, lacking information regarding their relative importance to mortality reduction, an issue for future study. Also worth studying is whether scores on more comprehensive practice attributes measures are associated with additional decrements in mortality. ${ }^{30}$ Finally, the attributes measure was based on patient report, raising the possibility of misreporting. Future studies should examine associations between mortality and primary care attributes scores derived using other methods, such as assessment by trained observers.

In conclusion, we found 2000-2005 MEPS respondents reporting greater access to selected primary care attributes had lower mortality during a follow-up of up to 6 years than respondents reporting less access to the attributes. Our findings advance the primary care evidence base and suggest that ongoing health care and primary care practice redesign efforts in the United States may have the potential to reduce preventable deaths. ${ }^{31}$

To read or post commentaries in response to this article, see it online at http://www.annfammed.org/content/10/1/34.

Key words: Access to health care; after-hours care; comprehensive health care; health care disparities; mortality; patient-centered care; patient-centered medical home; primary health care
Submitted April 19, 2011; submitted, revised, July 30, 2011; accepted August 8, 2011

\section{References}

1. Starfield B, Shi L, Macinko J. Contribution of primary care to health systems and health. Milbank Q. 2005;83(3):457-502.

2. Starfield B. Primary Care: Concept, Evaluation, and Policy. New York, NY: Oxford University Press; 1992.

3. Institute of Medicine, National Academy of Sciences. A Manpower Policy for Primary Health Care. Washington, DC: National Academies Press; 1978

4. Vest JR, Bolin JN, Miller TR, Gamm LD, Siegrist TE, Martinez LE. Medical homes: "where you stand on definitions depends on where you sit." Med Care Res Rev. 2010;67(4):393-411.

5. American Academy of Family Physicians (AAFP), American Academy of Pediatrics (AAP), American College of Physicians (ACP), American Osteopathic Association (AOA). Joint Principles of the Patient-centered Medical Home. http://www.medicalhomeinfo.org/downloads/ pdfs/jointstatement.pdf. Accessed Feb 22, 2011.

6. Friedberg MW, Hussey PS, Schneider EC. Primary care: a critical review of the evidence on quality and costs of health care. Health Aff (Millwood). 2010;29(5):766-772.

7. Morgenstern $\mathrm{H}$. Uses of ecologic analysis in epidemiologic research. Am J Public Health. 1982;72(12):1336-1344.

8. Medical Expenditure Panel Survey. Agency for Healthcare Research and Quality. August 21, 2009. http://www.meps.ahrq.gov/mepsweb /about_meps/survey_back.jsp. Accessed Dec 16, 2010.

9. US Department of Health and Human Services, Centers for Disease Control and Prevention, National Center for Health Statistics. NHIS linked mortality public use files. http://www.cdc.gov/nchs/ data_access/data_linkage/mortality/nhis_linkage_public_use.htm. Accessed Jun 29, 2010.

10. Tengs TO, Adams ME, Pliskin JS, et al. Five-hundred life-saving interventions and their cost-effectiveness. Risk Anal. 1995;15(3): 369-390.

11. Epstein RM, Franks P, Shields CG, et al. Patient-centered communication and diagnostic testing. Ann Fam Med. 2005;3(5):415-421.

12. Stewart M, Brown JB, Donner A, et al. The impact of patient-centered care on outcomes. J Fam Pract. 2000;49(9):796-804

13. Rust G, Ye J, Baltrus P, Daniels E, Adesunloye B, Fryer GE. Practical barriers to timely primary care access: impact on adult use of emergency department services. Arch Intern Med. 2008;168(15): 1705-1710.

14. Lowe RA, Localio AR, Schwarz DF, et al. Association between primary care practice characteristics and emergency department use in a Medicaid managed care organization. Med Care 2005;43(8):792-800.

15. Deyo RA. Cascade effects of medical technology. Annu Rev Public Health. 2002;23:23-44.

16. Jones $\mathrm{P}$, Elangbam B, Williams NR. Inappropriate use and interpretation of D-dimer testing in the emergency department: an unexpected adverse effect of meeting the "4-h target." Emerg Med J. $2010 ; 27(1): 43-47$.

17. Starfield B. Is US health really the best in the world? JAMA. 2000; 284(4):483-485

18. Brenner D, Elliston C, Hall E, Berdon W. Estimated risks of radiation-induced fatal cancer from pediatric CT. AJR Am J Roentgenol. 2001;176(2):289-296.

19. Smith-Bindman R, Lipson J, Marcus R, et al. Radiation dose associated with common computed tomography examinations and the associated lifetime attributable risk of cancer. Arch Intern Med. 2009;169(22):2078-2086. 
20. Ware J Jr, Kosinski M, Keller SD. A 12-Item Short-Form Health Survey: construction of scales and preliminary tests of reliability and validity. Med Care. 1996;34(3):220-233

21. DeSalvo KB, Fan VS, McDonell MB, Fihn SD. Predicting mortality and healthcare utilization with a single question. Health Serv Res. 2005;40(4):1234-1246.

22. Centers for Disease Control and Prevention, National Center for Health Statistics. NHANES I Epidemiologic Follow-up Survey (NHEFS) calibration sample for NDI matching methodology. September 17, 2009. http://www.cdc.gov/nchs/data/datalinkage/ mort_calibration_study.pdf. Accessed Jul 22, 2011.

23. Grumbach K, Grundy P. Outcomes of implementing patient centered medical home interventions. A review of the evidence from prospective evaluation studies in the United States. Patient-Centered Primary Care Collaborative. November 16, 2010. http://www.cms .org/uploads/GrumbachGrundy20100utcomesPCPCC.pdf. Accessed Jan 5, 2011.

24. Rittenhouse DR, Shortell SM. The patient-centered medical home: will it stand the test of health reform? JAMA. 2009;301(19):20382040.

25. Ferrante JM, Balasubramanian BA, Hudson SV, Crabtree BF. Principles of the patient-centered medical home and preventive services delivery. Ann Fam Med. 2010;8(2):108-116.
26. Reid RJ, Fishman PA, Yu O, et al. Patient-centered medical home demonstration: a prospective, quasi-experimental, before and after evaluation. Am J Manag Care. 2009;15(9):e71-e87.

27. Reid RJ, Coleman K, Johnson EA, et al. The Group Health medical home at year two: cost savings, higher patient satisfaction, and less burnout for providers. Health Aff (Millwood). 2010;29(5):835-843.

28. National Healthcare Disparities Report, 2009. Rockville, MD: Agency for Healthcare Research and Quality; 2010. AHRQ Publication No. 10-0004.

29. Beal AC, Doty MM, Hernandez SE, Shea KK, Davis K. Closing the divide: how medical homes promote equity in health care. Results from the Commonwealth Fund 2006 Health Care Quality Survey. June 2007. http://www.commonwealthfund.org/usr_doc/1035_Beal_ closing_divide_medical_homes.pdf. Accessed Mar 11, 2011.

30. Agency for Healthcare Research and Quality. CAHPS Clinician \& Group Survey with Patient-Centered Medical Home Items. http:// www.cahps.ahrq.gov/content/products/CG/PROD_CG_PCMH.asp? $p=1021$ ss $=213$. Accessed Mar 1, 2011.

31. The Commonwealth Fund. Why not the best? Results from the national scorecard on US health system performance, 2008. http://www. commonwealthfund.org/Content/Publications/Fund-Reports/2008/Jul/ Why-Not-the-Best--Results-from-the-National-Scorecard-on-U-S--HealthSystem-Performance--2008.aspx. Accessed Feb 28, 2011.

Please complete this form and mail to the following address or fax to Annals Circulation at 913-906-6080:

Annals of Family Medicine, Circulation Department, 11400 Tomahawk Creek Pkwy, Leawood, KS 66211-2680

Check if member of sponsoring organization: $\square$ AAFP $\square$ ABFM $\square$ STFM $\square$ ADFM

$\square$ AFMRD $\square$ NAPCRG $\square$ CFPC

ID number from label on your journal cover

OLD Information (Please print.)

\section{Name}

Company (if applicable)

Address (Street plus Apt or Ste)

City

Country

Postal Code (9-digit ZIP for US)

Telephone

Fax

E-Mail
NEW Information (Please print.)

\begin{tabular}{ll}
\hline Name \\
\hline Company (if applicable) \\
\hline Address (Street plus Apt or Ste) & \\
\hline City & Postal Code (9-digit ZIP for US) \\
\hline Country & Fax \\
\hline Telephone & \\
\hline E-Mail
\end{tabular}

